OPEN ACCESS

Edited by:

Sandro Loche,

Ospedale Microcitemico, Italy

Reviewed by:

Giorgio Radetti,

Ospedale di Bolzano, Italy

Chiara Guzzetti,

Ospedale Microcitemico, Italy

*Correspondence:

Asma Deeb

adeeb@seha.ae

Yazan Al Sanad

o-yalsanad@seha.ae

Specialty section:

This article was submitted to

Pediatric Endocrinology,

a section of the journal

Frontiers in Pediatrics

Received: 19 December 2021

Accepted: 31 January 2022

Published: 28 February 2022

Citation:

Deeb A, Al Yaarubi S, Abbas BB, Al Jubeh J, Chaturvedi D, Al Hassani $N$,

Mutair A, Al Masri N, Al Sanad Y, Al Shidhani A, Mahmoud NS, Alherbish A and Savage MO (2022) Patients' Perception of the Use of the EasyPod ${ }^{T M}$ Growth Hormone Injector

Device and Impact on Injection

Adherence: A Multi-Center Regional

Study. Front. Pediatr. 10:839278.

doi: $10.3389 /$ fped.2022.839278

\section{Patients' Perception of the Use of the

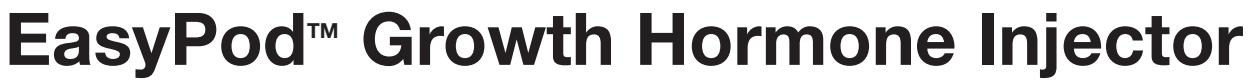 Device and Impact on Injection Adherence: A Multi-Center Regional Study}

\author{
Asma Deeb ${ }^{1 *}$, Saif Al Yaarubi ${ }^{2}$, Bassam Bin Abbas ${ }^{3}$, Jamal Al Jubeh ${ }^{4}$, Deepti Chaturvedi ${ }^{5}$, \\ Noura Al Hassani ${ }^{6}$, Angham Mutair ${ }^{7}$, Neamat Al Masri ${ }^{1}$, Yazan Al Sanad ${ }^{1 *}$, \\ Azza Al Shidhani ${ }^{2}$, Noha Samir Mahmoud ${ }^{8}$, Abdullah Alherbish ${ }^{8}$ and Martin O. Savage ${ }^{9}$ \\ ${ }^{1}$ Sheikh Shahbout Medical City \& Khalifa University, Abu Dhabi, United Arab Emirates, ${ }^{2}$ College of Medicine, Sultan Qaboos \\ University Hospital, Muscat, Oman, ${ }^{3}$ King Faisal Specialist Hospital and Research Center, Riyadh, Saudi Arabia, \\ ${ }^{4}$ Department of Pediatrics, Sheikh Khalifa Medical City, Abu Dhabi, United Arab Emirates, ${ }^{5}$ Department of Pediatrics, Burjeel \\ Hospital, Abu Dhabi, United Arab Emirates, ${ }^{6}$ Division of Endocrine and Diabetes, Department of Pediatrics, Tawam Hospital \\ and Faculty of Medicine and Health Science, UAE University, Al Ain, United Arab Emirates, ${ }^{7}$ Pediatric Endocrine Division, \\ Department of Pediatrics, King Abdulaziz Medical City, King Abdullah Specialist Children Hospital, Ministry of National Guard \\ Health Affairs, Riyadh, Saudi Arabia, ${ }^{8}$ Alhabib Medical Group, Riyadh, Saudi Arabia, ${ }^{9}$ Centre for Endocrinology, Barts and the \\ London School of Medicine \& Dentistry, William Harvey Research Institute, Queen Mary University of London, London, \\ United Kingdom
}

Objective: This study aimed to assess patient perceptions of the use of the EasyPod ${ }^{\mathrm{TM}}$ growth hormone delivery device and its association with compliance.

Methods: This cross-sectional, multicenter study was conducted in six centers from three countries (United Arab Emirates, Oman, and Saudi Arabia,) between March 2020 and June 2020. Children and adolescents aged 3-18 years, diagnosed with growth disorders and receiving $\mathrm{rhGH}$ through the EasyPod ${ }^{\mathrm{TM}}$ device were enrolled. Patients and caregivers were given a pre-set questionnaire that evaluated patient satisfaction, preference for technical and personalized features, and device drawbacks. The results were analyzed using independent measures of analysis of variance to evaluate the association of higher satisfaction with device features and better compliance.

Results: A total of 186 patients were enrolled in the study. Of these, $45.7 \%$ had $\mathrm{GH}$ deficiency. The mean age $( \pm S D)$ of patients was $11.8( \pm 2.76)$ years; $117(62.90 \%)$ were males. Average compliance was $87 \%$. One hundred patients (53.76\%) had injection compliance of $\geq 90 \%$. Amongst these patients, $74 \%$, $68 \%$, and $77 \%$ top-scored $(5 / 5)$ the technical features of hidden needle, skin sensor, and pre-set dosing, respectively, compared to top scores by 39\%, 34\%, and 51\% patients in the $<90 \%$ compliance group ( $p$-value $<0.05)$. Similarly, a statistically significant difference was observed between the groups ( $p$-value $<0.05$ ) in the perception of the usefulness of the tracking features such as display of history of injected doses (78\% vs. $47.7 \%$ ), a reminder for medicine remaining (46\% vs. $23.3 \%$ ) and battery power indicator (48\% vs. $20.9 \%$ ). Personal screen messages were associated with higher compliance while the requirement to keep the 
device in the fridge was reported as the most inconvenient feature by $56 \%$ of patients in the higher compliance group as against $39.5 \%$ in the lower compliance group ( $p$-value $<0.05)$. There was no statistically significant difference in the intensity of pain reported in the two compliance groups.

Conclusion: Our study showed that there is a statistically significant association between better perception of device features and higher compliance.

Keywords: EasyPod ${ }^{\mathrm{TM}}$, growth hormone deficiency, recombinant human growth hormone, injector device features, compliance

\section{INTRODUCTION}

The availability of recombinant human growth hormone (rhGH) has made GH treatment for short stature widely available (1). Growth hormone treatment has a wide list of indications, some of which have received approval from the Food and Drug Administration or European Medicines Agency. These include GH deficiency (GHD), Turner syndrome, short stature related to a birth size small for gestational age (SGA), idiopathic short stature, and growth failure in pre-pubertal children due to chronic renal insufficiency (CRF) (2-4).

GH therapy has been demonstrated to improve shortterm growth and adult height in approved indications (5). However, considerable variability in response has been noted depending on the age at the start of therapy, GH dose, genetic conditions, concomitant illness, and compliance $(3,6)$. As with any chronic long-term treatment, rhGH treatment is burdened with suboptimal adherence, especially in a pediatric population (7). Factors affecting adherence to GH therapy include the patients' preference for the GH delivery device, its simplicity, and convenience, as well as appropriate education and technical training (8). Daily subcutaneous GH injections can create a significant treatment load, negatively influencing adherence to therapy (2). Adherence to the recommended treatment regimen is important for successful outcomes with rhGH therapy to ensure that patients reach their target height (9). Low adherence is also associated with less favorable clinical outcomes and increased healthcare costs (10).

Several strategies have been proposed to improve adherence. These include improving device simplicity, convenience, and education and training of patients and parents (2). A recent survey of patients, parents, physicians and nurses with experience in the administration of rhGH suggested that reliability, ease of use, lack of pain during injection, safety in use and storage, and a minimum number of steps before injection preparation, were all important factors (10). In addition, a good tracking system to objectively monitor treatment adherence was considered extremely important by the treating physicians (10). Precise information on treatment adherence allows the clinician to exclude poor adherence as a possible reason for suboptimal growth response, driving further treatment adjustment (2). Multiple long-acting GH (LAGH) preparations are also currently being developed in an attempt to decrease GH injection frequency from daily to weekly, biweekly, or monthly, thereby attempting to improve adherence (11).
EasyPod $^{\mathrm{TM}}$ is an electronic auto-injector device that is equipped for adherence monitoring. It has several features including pre-set dosing, adjustable injection settings, and monitoring of adherence using an injection log that records injection history, which can be accessed by patients and clinicians to monitor adherence. The device is equipped with other functions such as screen reminders for battery life, medication cartridge filling, and the number of medication doses left to encourage better compliance. In addition, the device has specific features to encourage children to use it, including protective skin covers, colorful device screen outliners, customized screen messages, and screen photographs of the patients' choice. These features are intended to create a bond between children and their devices and improve compliance.

The present study was carried out to assess patient satisfaction with the technical and tracking features of the EasyPod $^{\mathrm{TM}}$ delivery device and its association with compliance. We also aimed to explore the most preferred personal features of the device, patients' scoring of pain severity, and drawbacks of the device. This users' feedback will enable the application of various improvement strategies on the device, encouraging better utilization with the ultimate aim of improving treatment adherence.

\section{MATERIALS AND METHODS}

\section{Structure of the Study}

This was a questionnaire-based, multicenter, survey study conducted from the 1st of March to the 30th of June 2020. The initial study was planned to be carried out at eight centers from three countries (United Arab Emirates, Oman, and Saudi Arabia), but due to the lack of compliance data from two centers, the final data analysis was carried out with data from six centers. A total of 186 children and adolescents diagnosed with growth disorders in the age group of 3-18 years and receiving $\mathrm{rGH}\left(\right.$ Saizen ${ }^{\circledR}$, Merck Serono International SA, Geneva, Switzerland) through the EasyPod ${ }^{\mathrm{TM}}$ (Merck Serono International SA, Geneva, Switzerland) device were enrolled in the survey. All enrolled subjects were on GH treatment for a variable period, with a mean $( \pm S D)$ duration of $3.74( \pm 2.9)$ years and were using the EasyPod ${ }^{\mathrm{TM}}$ device only. Participants above 12 years mostly self-injected, while younger children were helped by their parents/carers to inject. Informed consent was obtained from the participants and/or their parents. The patients' compliance to injectable therapy was reviewed by downloading 
the data recorded in the device and is taken as a percentage over the latest 3-6 months period of use.

The aim of the study and details of the questionnaire were explained to the participants by the study team consisting of pediatric endocrinologists and endocrine nurses. The study was approved by local institutional review boards.

\section{Scoring Systems Within the Questionnaire}

The questionnaire was designed by co-authors who formed a focus group to assess users' satisfaction and perception of use. It was validated for use by multiple trials in the clinic with staff and users before commencing the study. It included questions on five main areas related to the device (Appendix).

1. Patient satisfaction with the technical features (Q1)

2. Patients' views on tracking features and compliance support (Q2-3)

3. Patients' preferred personalized feature (Q4)

4. Patient scoring of pain on device use (Q5)

5. Experience on device drawbacks (Q6)

The Question on satisfaction with technical features (Q1) of the device was scored on a 5-point scale, with 1 being un-useful, 2 less useful, 3 neutral, 4 useful and 5 being very useful. Tracking features were assessed in 2 questions. Question 2 was scored on a 5 points scale (as above) and Question 3 was designed to have an answer of either "Yes," "No," or "Neutral." Inquiry on preferred personalized device features (Q4) was assessed through a multiple-choice question in which a list of personalized features was given to choose from. Pain intensity was scored on a 5- point scale, with 1 being completely painless, 2 minimal, 3 mild pain, 4 moderate pain and 5 being very painful (Q5). Views on device drawbacks were enquired about in a multiple-choice question which users scored for the most appropriate answer (Q6).

\section{Endpoints of the Survey}

The primary endpoint of the survey was to assess patient satisfaction with the technical and tracking features of the EasyPod $^{\mathrm{TM}}$ delivery device and its association with compliance. The secondary endpoint was to explore patients' preferred personalized device features, pain experience, and device drawbacks. Device compliance of $85 \%$ is considered to be satisfactory as per the literature $(9,12)$. However, considering the overall high compliance in our cohort, we considered compliance of $90 \%$ or more as the cut-off level to perform a segmental analysis on this proportion of patients.

\section{Statistics and Data Analysis}

Standard descriptive statistics and demographic and primary data analysis was carried out in 186 patients. The proportion analysis of patients who rated the automated dose delivery and tracking features as being "very useful" and helpful in tracking and increasing compliance was summarized using frequency count. Mean $( \pm S D)$ values were calculated for the baseline characteristics of patients' ages and duration of treatment with $\mathrm{GH}$. The data was divided into two subgroups based on compliance $(<90 \%$ compliance and $\geq 90 \%$ compliance). For ordinal data obtained from Q1, Q2, and Q5, the Kruskal-Wallis H test (sometimes also called the "one-way ANOVA on ranks") was used to determine if there are statistically significant differences between the two groups (compliance $<90 \%$ vs. $\geq 90 \%$ ) to an independent variable on a continuous dependent variable. For categorical data (Q3, Q4, Q6), univariate logistic regression analysis was used for statistically significant differences between two or more groups (compliance $<90 \%$ vs. $\geq 90 \%$ ).

\section{RESULTS}

\section{Subjects and Diagnoses}

A total of 186 subjects were enrolled from six centers in three countries (Center 1: 32, Center 2: 12, Center 3: 17, Center 4: 65, Center 5: 40, Center 6: 20). The mean age \pm SD of the enrolled patients was $11.8 \pm 2.76$ years. There were 117 males and 65 females in the study. Gender information was missing for four patients. The mean \pm SD duration of treatment with growth hormone was $3.74 \pm 2.9$ years. The mean percentage of compliance recorded was $87 \%$ (range: $50-100 \%$ ). A hundred patients $(53.76 \%)$ had injection compliance of $\geq 90 \%$; mean compliance in this group was $95 \%$ (range: $90-100 \%$ ). The average duration of use of the device in these patients was $3.49 \pm 2.98$ years compared to $3.56 \pm 2.33$ in the 86 patients with $<90 \%$ compliance (mean compliance of 79\%; range: 50-89\%). Twentynine patients had $100 \%$ compliance and the average duration of use in these patients was $2.57 \pm 2.76$ years. The majority of patients were diagnosed with GH deficiency $(48.9 \%)$ of which 6 patients $(6.6 \%)$ had panhypopituitarism. Other diagnoses were idiopathic short stature (21.5\%), small for gestational age (15.6\%), chronic renal failure (3.2\%), and Turner's syndrome (3.2\%). Other conditions included were Noonan syndrome (2.7\%), skeletal dysplasia (2.2\%), Fanconi Bickel syndrome (1.1\%), rheumatoid disease $(0.5 \%)$, and osteogenesis imperfecta (0.5\%). Data on diagnosis was missing for one patient (Table 1).

\section{Scoring of Automated Dose Delivery Features of the Device}

The data set for the primary endpoint analysis comprised of 186 patients. The technical features of the device were scored as follows: $74 \%$ of patients in the higher compliance group of $\geq 90 \%$ reported the hidden needle feature to be "very useful" compared to $45.3 \%$ in the lower compliance group. Similarly, the skin sensor and pre-set dosing facility were scored as "very useful" by 68 and $77 \%$ of patients, respectively, in the higher compliance group as compared to 39.5 and $59.3 \%$ in the lower compliance group (Table 2). A Kruskal-Wallis $\mathrm{H}$ test showed that there was a statistically significant difference in perception regarding the usefulness of the hidden needle feature between the two compliance groups ( $<90 \%$ vs. $\geq 90 \%$, $\left[\chi^{2}(1)=18.943, p<\right.$ $0.001]$ ), with a mean rank of 77.31 in the $<90 \%$ compliant group and 107.42 in the $\geq 90 \%$ compliant group. Similarly, patients in the $\geq 90 \%$ compliance group were statistically significantly more satisfied with the skin sensor feature [mean rank of 78.80 in the $<90 \%$ compliance group and 106.14 in the $\geq 90 \%$ compliance group; $\chi^{2}(1)=14.756, p<0.001$ ], and the pre-set dosing feature [mean rank of 84.56 in the $<90 \%$ compliance group and 101.18 
TABLE 1 | Baseline demographic profile $(N=186)$.

\begin{tabular}{|c|c|}
\hline Mean $( \pm S D)$ age & $11.8( \pm 2.76)$ \\
\hline Sex ratio $(M: F)^{a}$ & $117: 65$ \\
\hline \multicolumn{2}{|l|}{ GH indication ${ }^{\mathrm{b}} N(\%)$} \\
\hline GH deficiency $N(\%)$ & $91(48.9)$ \\
\hline Panhypopituitarism & $6(6.6 \%)^{c}$ \\
\hline Idiopathic short stature $N(\%)$ & $40(21.5)$ \\
\hline Small for gestational age N (\%) & $29(15.6)$ \\
\hline Chronic renal failure $N(\%)$ & $6(3.2)$ \\
\hline Turners syndrome $N(\%)$ & $6(3.2)$ \\
\hline Noonan syndrome N (\%) & $5(2.7)$ \\
\hline Skeletal dysplasia $N(\%)$ & $4(2.2)$ \\
\hline Fanconi Bickel syndrome N (\%) & $2(1.1)$ \\
\hline Rheumatoid disease N (\%) & $1(0.5)$ \\
\hline Osteogenesis imperfect $N(\%)$ & $1(0.5)$ \\
\hline Total & 185 \\
\hline Duration of GH indication in years [Mean $( \pm S D)]$ & $3.74( \pm 2.9)$ \\
\hline Average compliance (\%) & $87 \%$ \\
\hline Mean compliance (<90\%) (Range) & $79 \%(50-89 \%)$ \\
\hline Mean compliance ( $\geq 90 \%)$ (Range) & $95 \%(90-100 \%)$ \\
\hline
\end{tabular}

${ }^{a}$ Gender information is missing for four patients.

${ }^{b}$ Indication data is missing for one patient.

${ }^{c}$ Proportion of patients with GH deficiency.

in the $\geq 90 \%$ compliance group; $\left.\chi^{2}(1)=6.616, p=0.010\right]$ compared to patients in the $<90 \%$ compliance group.

\section{Tracking Features}

Among the tracking features, a statistically significant higher proportion of patients $(78 \%)$ in the $\geq 90 \%$ compliance group reported the feature of the history of injected and missed doses to be "very useful" as compared to $47.7 \%$ in the $<90 \%$ compliance group ( $<90 \%$ vs. $\geq 90 \%$, [ $\left.\chi^{2}(1)=23.266, p<0.001\right]$ ) (Table 2 ), with a mean rank of 75.92 in the $<90 \%$ compliance group and 108.62 in the $\geq 90 \%$ compliance group.

The feature of medicine left in cartridge reminder and the battery power indicator was rated to be "very useful" by 46 and $48 \%$, respectively, by patients in the higher compliance group (Table 2). This was significantly higher than the patients in the lower compliance group $(23.3$ and $20.9 \%)(p<0.001)$. A Kruskal-Wallis $\mathrm{H}$ test showed that there was a statistically significant difference in perception regarding the cartridge change notification feature between the different compliance groups $\left[<90 \%\right.$ vs. $\geq 90 \%$; $\left.\chi^{2}(1)=17.908, p<0.001\right]$, with a mean rank of 76.18 in the $<90 \%$ compliance group and 108.40 in the $\geq 90 \%$ compliance group. Similarly, a Kruskal-Wallis $\mathrm{H}$ test showed that there was a statistically significant difference in perception regarding the battery power left notification feature between the different compliance groups $\left[<90 \%\right.$ vs. $\geq 90 \% ; \chi^{2}$ $(1)=20.375, p<0.001$ ], with a mean rank of 74.96 in the $<90 \%$ compliance group and 109.44 in the $\geq 90 \%$ compliance group.

Among highly compliant patients, $80 \%$ found the tracking features of the device to be useful in tracking missed doses and in encouraging their child to be more compliant. However, a Chi-square test showed that this number was not statistically significantly higher $\left[\chi^{2}(1)=1.183, p=0.277\right]$ than that in the lower compliance group $(<90 \%)$.

\section{Personalized Features}

A Chi-square test was not statistically significant between compliance groups in choice of personalized device features such as colorful covers $\left[\chi^{2}(1)=1.151, p=0.562\right]$, device skins $\left[\chi^{2}\right.$ $(1)=0.058, p=0.810]$ and welcome picture $\left[\chi^{2}(1)=0.786\right.$, $p=0.375]$. However, the personal screen message feature was significantly $\left[\chi^{2}(1)=4.212, p=0.040\right]$ associated with a higher ( $\geq 90 \%$ ) compliance status (Table 3 ).

\section{Pain on Injection}

In the higher compliance group, $48 \%$ of patients reported no pain experience on using the device (score of 1/5) and none reported a score of 5/5 (indicative of severe pain). Further, $49 \%$ of patients reported minimal to mild pain (scores of $2 / 5$ and 3/5) in this group. However, a Kruskal-Wallis $\mathrm{H}$ test showed that there was no statistically significant difference in pain scores between the two compliance groups $\left[<90 \%\right.$ vs. $\geq 90 \%$; $\chi^{2}(1)=1.359, p=$ $0.244]$, with a mean rank of 97.10 for compliance $<90 \%$ and 88.55 for compliance $\geq 90 \%$ (Table 4 ).

\section{Most Inconvenient Feature}

The requirement of keeping the device in the fridge was reported as the most inconvenient feature in the higher compliance group by $56 \%$ of patients as compared to $39.5 \%$ patients in the lower compliance group ( $p$-value $<0.05$ ). However, there was no statistically significant association between choice of others features such as special batteries $\left[\chi^{2}(1)=3.395, p=0.183\right]$, special needles $\left[\chi^{2}(1)=3.145, p=0.208\right]$ and heavy device $\left[\chi^{2}(1)=4.555, p=0.103\right]$ as being the most inconvenient, and compliance status (Table 5).

An analysis to evaluate the association between the scores and age of the patient did not show any statistically significant difference ( $\leq 10$ years and $>10$ years).

\section{DISCUSSION}

In the present study, patients and their parents or caregivers were surveyed over 4 months to evaluate patients' perception of various functionalities of the device and its impact on compliance. The study demonstrated a high GH treatment compliance in children and adolescents (87\%), which is more than the minimum percentage recommended to be considered as optimal adherence to hGH administration $(85 \%)(9,12)$. The present study results demonstrated that higher scores of patient satisfaction with the technical and the tracking features of the EasyPod $^{\mathrm{TM}}$ delivery device were significantly associated with higher compliance.

Over the years, several attempts have been made to understand patient needs and improve device design. The traditional syringes with needles have been replaced with more innovative user-friendly devices that include injection pens, self-injection pens, needle-free devices, and electronic devices with the potential to improve adherence. Adherence to treatment plays a vital role in 
TABLE 2 | Comparison between compliance groups for the usefulness of automated dose delivery and tracking features $(N=186)$.

\begin{tabular}{|c|c|c|c|c|c|c|}
\hline & & $\begin{array}{c}\text { Compliance } \\
(<90 \%)^{\star} \\
(n=86)\end{array}$ & $\begin{array}{c}\text { Compliance } \\
(\geq 90 \%)^{*} \\
(n=100)\end{array}$ & $\begin{array}{c}\text { Total }^{*} \\
(n=186)\end{array}$ & $\begin{array}{c}\chi^{2} \text { test } \\
\text { statistics }\end{array}$ & $P$-value \\
\hline \multicolumn{7}{|l|}{ Automated dose delivery features } \\
\hline \multirow[t]{5}{*}{ Hidden needle that auto-injects the medicine } & Un-useful & $0(0.0)$ & $0(0.0)$ & $0(0.0)$ & 18.943 & $<0.001$ \\
\hline & Less useful & $9(10.5)$ & $1(1.0)$ & $10(5.4)$ & & \\
\hline & Neutral & $16(18.6)$ & $7(7.0)$ & $23(12.4)$ & & \\
\hline & Useful & $22(25.6)$ & $18(18.0)$ & $40(21.5)$ & & \\
\hline & Very Useful & $39(45.3)$ & $74(74.0)$ & $113(60.8)$ & & \\
\hline \multirow[t]{5}{*}{ Skin sensor that helps with injection technique } & Un-useful & $0(0.0)$ & $0(0.0)$ & $0(0.0)$ & 14.756 & $<0.001$ \\
\hline & Less useful & $4(4.7)$ & $\mathrm{O}(0.0)$ & $4(2.2)$ & & \\
\hline & Neutral & $15(17.4)$ & $11(11.0)$ & $26(14.0)$ & & \\
\hline & Useful & $33(38.4)$ & $21(21.0)$ & $54(29.0)$ & & \\
\hline & Very Useful & $34(39.5)$ & $68(68.0)$ & $102(54.8)$ & & \\
\hline \multirow[t]{5}{*}{ Preset dosing so no daily dialing is required } & Un-useful & $0(0.0)$ & $1(1.0)$ & $1(0.50)$ & 6.616 & 0.010 \\
\hline & Less useful & $0(0.0)$ & $0(0.0)$ & $0(0.0)$ & & \\
\hline & Neutral & $15(17.4)$ & $8(8.0)$ & $23(12.4)$ & & \\
\hline & Useful & $20(23.3)$ & $14(14.0)$ & $34(18.3)$ & & \\
\hline & Very Useful & $51(59.3)$ & $77(77.0)$ & $128(68.8)$ & & \\
\hline \multicolumn{7}{|l|}{ Tracking features } \\
\hline \multirow[t]{5}{*}{ History of injected and missed doses } & Un-useful & $14(16.3)$ & $2(2.0)$ & $16(8.6)$ & 23.266 & $<0.001$ \\
\hline & Less useful & $4(4.7)$ & $0(0)$ & $4(2.2)$ & & \\
\hline & Neutral & $14(16.3)$ & $6(6.0)$ & $20(10.8)$ & & \\
\hline & Useful & $13(15.1)$ & $14(14.0)$ & $27(14.5)$ & & \\
\hline & Very Useful & $41(47.7)$ & $78(78.0)$ & $119(64.0)$ & & \\
\hline \multirow{5}{*}{$\begin{array}{l}\text { Amount of medicine left in cartridge reminding } \\
\text { patients of time to change cartridge }\end{array}$} & Un-useful & $7(8.1)$ & $2(2.0)$ & $9(4.8)$ & 17.908 & $<0.001$ \\
\hline & Less useful & $15(17.4)$ & $5(5.0)$ & $20(10.8)$ & & \\
\hline & Neutral & $24(27.9)$ & $19(19.0)$ & $43(23.1)$ & & \\
\hline & Useful & $20(23.3)$ & 28 (28.0) & $48(25.8)$ & & \\
\hline & Very Useful & 20 (23.3) & $46(46.0)$ & 66 (35.5) & & \\
\hline \multirow[t]{5}{*}{ Battery power left } & Un-useful & 15 (17.4) & $4(4.0)$ & 19 (10.2) & 20.375 & $<0.001$ \\
\hline & Less useful & $9(10.5)$ & $9(9.0)$ & $18(9.7)$ & & \\
\hline & Neutral & $26(30.2)$ & $14(14.0)$ & 40 (21.5) & & \\
\hline & Useful & $18(20.9)$ & $25(25.0)$ & $43(23.1)$ & & \\
\hline & Very Useful & $18(20.9)$ & $48(48.0)$ & $66(35.5)$ & & \\
\hline
\end{tabular}

${ }^{*} n(\%)$.

TABLE 3 | Comparison between compliance groups for the preferred personalized device features $(N=186)$.

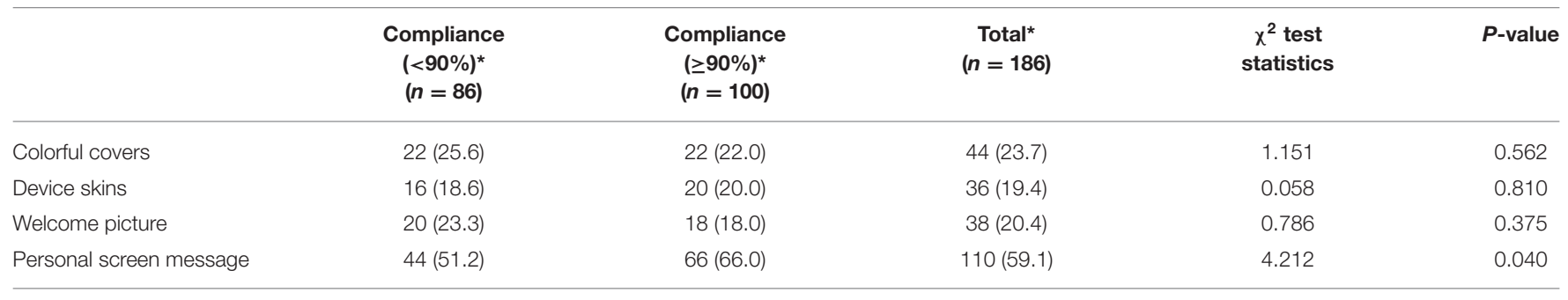

${ }^{*} n(\%)$.

the overall clinical outcomes of GH therapy (3). In a large multinational, observational study enrolling children receiving $\mathrm{GH}$ treatment through the EasyPod ${ }^{\mathrm{TM}}$ device, conducted between 2010 and 2016, it was observed that better adherence to treatment resulted in significant positive growth outcomes (13). Poor compliance resulted in significantly lower growth rates in comparison to patients who missed fewer doses (14). 
TABLE 4 | Comparison between compliance groups for the perception of pain with EasyPod ${ }^{\mathrm{TM}}$ device $(N=186)$.

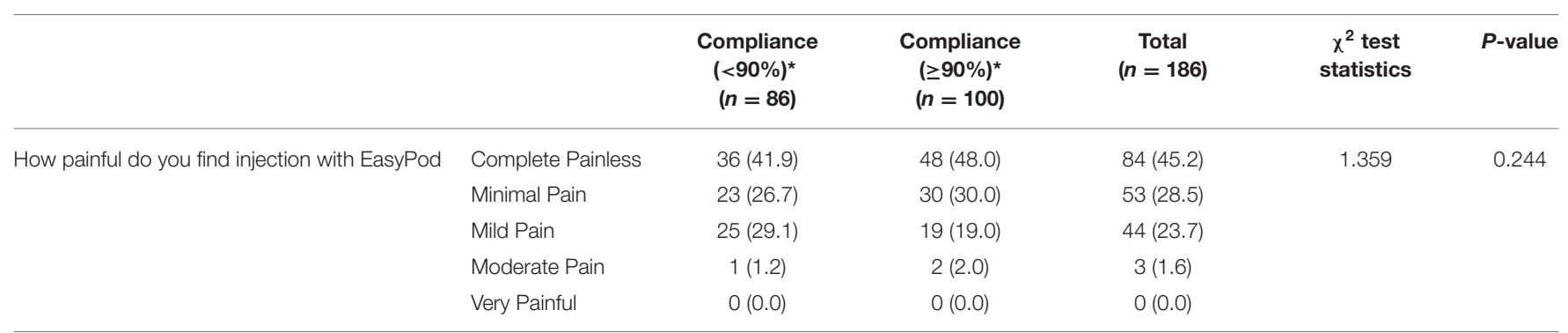

${ }^{*} n(\%)$.

TABLE 5 | Comparison between compliance groups for the most inconvenient feature of the device.

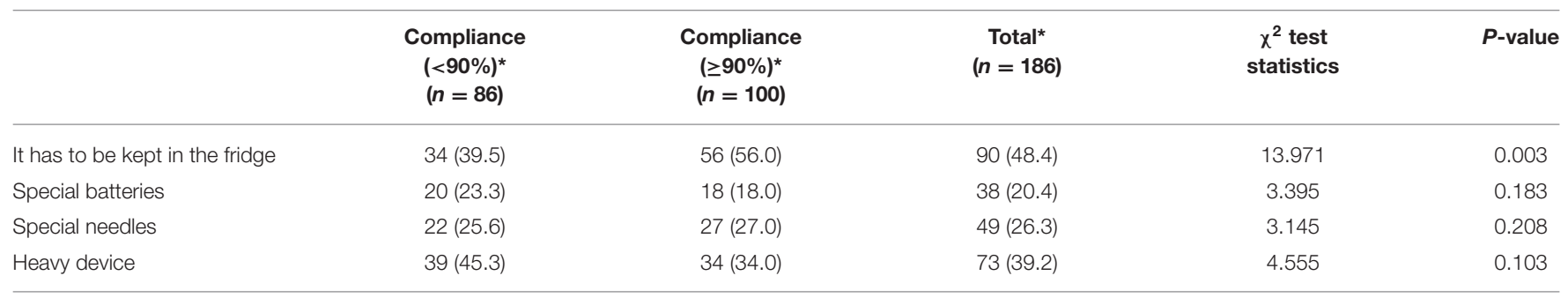

${ }^{*} n$ (\%).

Studies have suggested that decreased adherence may occur with increasing duration of treatment due to lack of enthusiasm or motivation about adhering to treatment compared with those new users, who may be more diligent (15). In the study by Koledova et al., median adherence rates were high (94\%) in the first year of treatment which gradually decreased over followup, but a majority of patients maintained $\geq 80 \%$ of adherence over 3 years of treatment (13). In our study too, the average duration of use in patients who had $100 \%$ compliance was 2.57 \pm 2.76 years, while the entire study population which reported an average duration of use of $3.74 \pm 2.9$ years showed a lower compliance rate of $87 \%$.

Most common device-related features that impact adherence levels as reported by parents include the product delivery system, its simplicity, convenience, and ease of use, and availability of appropriate training in the administration technique (8, 16). In a study to compare the optimum device for $\mathrm{GH}$ administration, a vial combined with an auto-injector or a pen injection system using a cartridge was compared. The study showed that patients preferred auto-injection devices over manual insertion of a needle (17). Dahlgren et al. showed that the auto-injector and skin sensor features of the EasyPod ${ }^{\mathrm{TM}}$ device help in increasing the accuracy of auto-injection (18). In an observational 3 month survey with children receiving r-hGH through EasyPod ${ }^{\mathrm{TM}}, 82.5 \%$ of participants found the electronic auto-injector easy/very easy to prepare, $92.4 \%$ of patients said that the device was easy/very easy to use, $85.0 \%$ rated the duration of injection as short/very short and $61.5 \%$ reported experiencing no pain when injecting with the electronic auto-injector (19). In our study too, patients were significantly more satisfied with the automated dose delivery features of the hidden needle, skin sensor, and pre-set dosing of the EasyPod $^{\mathrm{TM}}$ device and reported a higher compliance rate of $\geq 90 \%$.

The EasyPod ${ }^{\mathrm{TM}}$ device also has improvised display features. The display screen is larger compared to other devices and features high contrast and resolution to be easily read. Studies have shown that the provision of clear instructions affects patient preference for an injection device (20). Our study also demonstrated a high preference for personal screen messages by participants which was associated with higher compliance as well.

In a survey of another autoinjector GH administration device (Sure $\mathrm{Pal}^{\mathrm{TM}}$ ), patients or their caregivers rated the dose-memory function as being very helpful/helpful (66.2\%). The EasyPod ${ }^{\mathrm{TM}}$ device also has an inbuilt electronic adherence monitoring system that provides physicians with personal adherence data. A significantly higher number of patients in the high compliance group of $\geq 90 \%$ found the downloadable and tracking feature of the device to be useful in tracking injected and missed doses. Various other functions such as screen reminders for battery life and medication cartridge filling are also associated with higher compliance.

Stanhope et al., showed that patients experienced less pain with the auto-injector as compared to the pen and also reported less wastage of growth hormone (17). The high patient acceptance and satisfaction of the device in our study are aligned with a favorable safety profile and a high proportion of subjects reporting no pain (45.2\%). None of the patients surveyed reported severe pain, and only 3 reported moderate pain as per the pain scale used. We hypothesize that the hidden needle feature of the device could be a factor in reducing the pain as the feature was rated highly by the majority of the subjects. It 
is reported that the hidden needle feature is less likely to make the patient anxious and consequently less sensitive toward pain (21). However, there is no statistically significant association in the perception of pain with EasyPod ${ }^{\mathrm{TM}}$ and higher compliance.

It can be anticipated that parents well-informed on the diagnosis, and the modalities and problems related to treatment might be more motivated to do the best for their children, to know all possibilities offered by the device. This would once again underline the importance of accurate information given to the parent at the beginning of treatment in order to obtain a better result.

The current study results are in agreement with previous studies using smaller sample sizes and shorter duration and indicate a high level of patient acceptance of the electronic auto-injector for the daily administration of GH. The features of EasyPod ${ }^{\mathrm{TM}}$ are considered useful in routine practice and a majority of participants express a desire to continue using the device (22). Patient feedback on drawbacks and pain scores can also provide a basis for improving the technical features and better utilizing the comfort setting for further improving compliance.

A limitation of the study was the design being a crosssectional open-label survey. The comparison between treatment-naïve and treatment-experienced could not be done. A controlled longitudinal design can be envisaged in the future.

\section{CONCLUSIONS}

Patients in the $\geq 90 \%$ compliance group were more satisfied with the automated dose delivery and tracking features of the EasyPod $^{\mathrm{TM}}$ device in comparison to those with lesser compliance.

\section{REFERENCES}

1. Grimberg A, DiVall SA, Polychronakos C, Allen DB, Cohen LE, Quintos $\mathrm{JB}$, et al. Guidelines for growth hormone and insulin-like growth factor-I treatment in children and adolescents: growth hormone deficiency, idiopathic short stature, and primary insulin-like growth factor-I deficiency. Horm Res Paediatr. (2016) 86:361-97. doi: 10.1159/000452150

2. Maggio MC, Vergara B, Porcelli P, Corsello G. Improvement of treatment

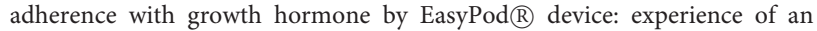
Italian centre. Ital J Pediatr. (2018) 44:113. doi: 10.1186/s13052-018-0548-z

3. Lee PA, Germak J, Gut R, Khutoryansky N, Ross J. Identification of factors associated with good response to growth hormone therapy in children with short stature: results from the ANSWER Program $®$. Int J Pediatr Endocrinol. (2011) 2011:6. doi: 10.1186/1687-9856-2011-6

4. Pfäffle. R. Hormone replacement therapy in children: the use of growth hormone and IGF-I. R Best Pract Res Clin Endocrinol Metab. (2015) 29:33952. doi: 10.1016/j.beem.2015.04.009

5. Collett-Solberg PF, Ambler G, Backeljauw PF, Bidlingmaier M, Biller BMK, Boguszewski MCS, et al. Diagnosis, genetics, and therapy of short stature in children: a Growth Hormone Research Society International Perspective. Horm Res Paediatr. (2019) 92:1-14. doi: 10.1159/000502231

6. Bang P, Bjerknes R, Dahlgren J, Dunkel L, Gustafsson J, Juul A, et al. A comparison of different definitions of growth response in short prepubertal children treated with growth hormone. Horm Res Paediatr. (2011) 75:33545. doi: $10.1159 / 000322878$
Formal education of the device's advanced technical features may further improve satisfaction and ensure injection compliance.

\section{DATA AVAILABILITY STATEMENT}

The original contributions presented in the study are included in the article/Supplementary Material, further inquiries can be directed to the corresponding author/s.

\section{ETHICS STATEMENT}

The studies involving human participants were reviewed and approved by Sheikh Shakhbout Medical City Research Ethics Committee. Written informed consent to participate in this study was provided by the participants' legal guardian/next of kin.

\section{AUTHOR CONTRIBUTIONS}

$\mathrm{AD}$ designed the study, collected site data, and liaised between co-authors. All authors contributed equally to the development of the manuscript.

\section{ACKNOWLEDGMENTS}

Dr. Rupali Bahri from Medcytes, Dubai provided medical writing services for the development of this manuscript.

\section{SUPPLEMENTARY MATERIAL}

The Supplementary Material for this article can be found online at: https://www.frontiersin.org/articles/10.3389/fped. 2022.839278/full\#supplementary-material
7. Fisher BG, Acerini CL. Understanding the growth hormone therapy adherence paradigm: a systematic review. Horm Res Paediatr. (2013) 79:18996. doi: $10.1159 / 000350251$

8. Bhosle M, Klingman D, Aagren M, Wisniewski T, Lee WC. Human growth hormone treatment: synthesis of literature on product delivery systems and administration practices. J Spec Pediatr Nurs. (2011) 16:5063. doi: 10.1111/j.1744-6155.2010.00267.x

9. Cutfield WS, Derraik JG, Gunn AJ, Reid K, Delany T, Robinson $\mathrm{E}$, et al. Non-compliance with growth hormone treatment in children is common and impairs linear growth. PLoS ONE. (2011) 6:e16223. doi: 10.1371/journal.pone.0016223

10. Loche S, Salerno M, Garofalo P, Cardinale GM, Licenziati MR, Citro G, et al. Adherence in children with growth hormone deficiency treated with r-hGH and the EasyPod ${ }^{\mathrm{TM}}$ device. J Endocrinol Invest. (2016) 39:1419424. doi: 10.1007/s40618-016-0510-0

11. Miller BS, Velazquez E, Yuen KCJ. Long-acting growth hormone preparations - current status and future considerations. J Clin Endocrinol Metab. (2020) 105:e2121-33. doi: 10.1210/clinem/dgz149

12. Arnao MDR, Sanchez AR, Lopez ID, Fernandez JR, de la Vega JAB, Fernandez DY, et al. Adherence and long-term outcomes of growth hormone therapy with EasyPod ${ }^{\mathrm{TM}}$ in pediatric subjects: Spanish ECOS study. Endocr Connect. (2019) 8:1240-9. doi: 10.1530/EC-19-0325

13. Koledova E, Tornincasa V, van Dommelen P. Analysis of real-world data on growth hormone therapy adherence using a connected injection device. $B M C$ Med Inform Decis Mak. (2020) 20:176. doi: 10.1186/s12911-020-01183-1 
14. Desrosiers P, O'Brien F, Blethen S. Patient outcomes in the GH Monitor: the effect of delivery device on compliance and growth. Pediatr Endocrinol Rev. (2005) 2(Suppl. 3):327-31.

15. Costello K, Kennedy P, Scanzillo. Recognizing nonadherence in patients with multiple sclerosis and maintaining treatment adherence in the long term. $J$ Medscape J Med. (2008) 10:225.

16. Kappelgaard AM, Laursen T. The benefits of growth hormone therapy in patients with Turner syndrome, Noonan syndrome and children born small for gestational age. Growth Horm IGF Res. (2011) 21:30513. doi: 10.1016/j.ghir.2011.09.004

17. Stanhope R, Albanese A, Moyle L, Hamill G. Optimum method for administration of biosynthetic human growth hormone: a randomised crossover trial of an auto injector and a pen injection system. Arch Dis Child. (1992) 67:994. doi: 10.1136/adc.67.8.994

18. Dahlgren J, Veimo D, Johansson L, Bech I. Patient acceptance of a novel electronic auto- injector device to administer recombinant human growth hormone: results from an open- label, user survey of everyday use. Curr Med Res Opin. (2007) 23:1649-55. doi: 10.1185/030079907X210589

19. Bozzola M, Pagani S, Iughetti L, Maffeis C, Bozzola E, Meazza C. Adherence to growth hormone therapy: a practical approach. Horm Res Paediatr. (2014) 81:331-5. doi: 10.1159/000357975

20. Gluckman PD, Cutfield WS. Evaluation of a pen injector system for growth hormone treatment. Arch Dis Child. (1991) 66:686-8. doi: 10.1136/adc.66.6.686

21. Dahlgren J. Easypod: a new electronic injection device for growth hormone. Expert Rev Med Devices. (2008) 5:297-304. doi: 10.1586/17434440. 5.3.297

22. Tauber M, Payen C, Cartault A, Jouret B, Edouard T, Roger D. User trial of Easypod, an electronic autoinjector for growth hormone. Ann Endocrinol. (2008) 69:511-6. doi: 10.1016/j.ando.2008. 04.003

Conflict of Interest: This publication received funding from Merck Serono Middle East FZ-LTD. The funder was not involved in the study design, collection, analysis, interpretation of data, the writing of this article, or the decision to submit it for publication. This publication is done via an unrestricted medical writing grant by Merck Serono Middle East FZ-LTD, an affiliate of Merck KGaA, Darmstadt, Germany.

The authors declare that the research was conducted in the absence of any commercial or financial relationships that could be construed as a potential conflict of interest.

Publisher's Note: All claims expressed in this article are solely those of the authors and do not necessarily represent those of their affiliated organizations, or those of the publisher, the editors and the reviewers. Any product that may be evaluated in this article, or claim that may be made by its manufacturer, is not guaranteed or endorsed by the publisher.

Copyright (c) 2022 Deeb, Al Yaarubi, Abbas, Al Jubeh, Chaturvedi, Al Hassani, Mutair, Al Masri, Al Sanad, Al Shidhani, Mahmoud, Alherbish and Savage. This is an open-access article distributed under the terms of the Creative Commons Attribution License (CC BY). The use, distribution or reproduction in other forums is permitted, provided the original author(s) and the copyright owner(s) are credited and that the original publication in this journal is cited, in accordance with accepted academic practice. No use, distribution or reproduction is permitted which does not comply with these terms. 